\title{
Development of Textile Natural Dyeing using Hybrid Dyes from Mango Leaves Turmeric
}

\author{
Nita Kusumawati*, Samik \\ dept. of Chemistry \\ Universitas Negeri Surabaya \\ Surabaya, Indonesia \\ nitakusumawati@unesa.ac.id
}

\author{
Agus Budi Santoso \\ dept. of Electrical Engineering \\ Universitas Negeri Surabaya \\ Surabaya, Indonesia
}

\author{
Asri Wijiastuti \\ dept. of Special Education \\ Universitas Negeri Surabaya \\ Surabaya, Indonesia
}

\begin{abstract}
In this study, natural staining procedures have been evaluated using hybrid dyes of mango and turmeric leaves. To get rich color shades with high strength and color fastness, coloring is done by involving a number of preparation stages which include washing using Turkish Red Oil (TRO), mordanting using alum, and staining which ends with fixation using iron material (II ) sulfate (tunjung), alum and lime. The results showed the appearance of dark blue (dark), greenish yellow and yellow from the staining results using mango leaf extract as a single dye, each of which was fixed using tunjung, alum and lime, while in natural coloring with turmeric extract as a single dye with all three types of fixer the same each produces shades of brown, bright yellow and cream. The combination of mango and turmeric leaf extract as a hybrid coloring material has enriched the color shades produced with color strength $\mathbf{7 8 . 6 4 \%} \mathbf{- 9 0 . 1 6 \%}$ for $\mathbf{2 5 \%}$ DM / 75\% K; $77.33 \%$ $-\mathbf{9 0 . 7 0} \%$ to $\mathbf{5 0} \% \mathrm{DM} / \mathbf{5 0} \% \mathrm{~K}$; and $\mathbf{7 5 . 8 7 \%}-\mathbf{- 8 7 . 3 6 \%}$ for $\mathbf{7 5 \%}$ DM / 25\% K. Furthermore, the use of hybrid dyes from a combination of mango and turmeric leaf extract has resulted in high color fastness. This can be seen from the staining scale of each dye, ie 2-3 (less) - 4 (good) for $25 \%$ DM / 75\% K; 3-4 (good enough) - 4 (good) for $50 \% \mathrm{DM} / 50 \% \mathrm{~K}$; and 3 (enough) - 3-4 (good enough) for $75 \% \mathrm{DM} / 25 \% \mathrm{~K}$.
\end{abstract}

Keywords-Textile, Dyes, Natural, Mango leaves, Turmeric

\section{INTRODUCTION}

Small industries have a very large role in development Indonesian economy. In 2003, a small industrial sector that was able to absorb $99.4 \%$ of the Indonesian workforce. One of the small industries that absorbs the most labor is the batik industry. The development of the batik industry from the beginning was recognized by UNESCO as a nonIndonesian original cultural heritage [1].

Unfortunately, the rapid development of the batik industry is not accompanied by an increase in awareness of batik craftsmen and entrepreneurs to attend and to manage their production waste [2]. During this time, a large amount of liquid waste produced every day by batik UMKM in almost all parts of Indonesia, was immediately thrown into the body of water [3]. This condition is worrying, considering that $15-85 \%$ of the total textile dyes are used, they do not bind to fabric fibers and are wasted as waste effluent [4] - [5]. The percentage of dyes that pass as an effluent increases the potential for environmental damage that can be caused [6]. One of the solutions to this problem is to minimize the use of synthetic dyes and re-promote the use of environmentally friendly natural dyes.
Natural textile dyes are generally obtained from extracts of various parts of plants such as roots, wood, leaves, seeds or flowers. Batik craftsmen have known many plants that can color textiles, such as: Indigo tree leaves (Indigofera), skin of soga tingi trees (Ceriops candolleana arn), tegeran wood (Cudraina javanensis), turmeric (Curcuma), tea (Tea), noni roots ( Morinda citrifelia), soga jambal skin (Pelthophorum ferruginum), kesumba (Bixa orelana), guava leaves (Psidium guajava) [7]. However, until now there has never been reported standardization of coloring preparations using natural dyes, as well as testing the color quality resulting from natural coloring. Standardization of natural coloring preparations from various source materials will greatly determine the homogeneity of coloring. The creation of the Standard Operating Procedure (SOP) for the preparation of natural dyes through this research, will make the quality of the coloring of batik cloth homogeneous and not dependent on the skills of the Human Resources (HR) who are the executors of coloring.

Mango (Mangifera indica L.) is a medicinal plant that belongs to the Anacardiaceae family. Mango is a plant native to Southeast Asia that is widely distributed to most tropical regions of the world. Mango is the third most popular tropical fruit worldwide and its production produces considerable agro-industrial wastes, such as skin, kernel seeds, leaves and bark derived from pruning and fruit processing industries. Many studies have shown that mango leaves are one of the main sources of polyphenols with powerful antioxidant functions and other pharmacological properties [8] - [9]. Mangiferin is one of the dominant polyphenols in mango leaves that has a function as a natural dye and has several pharmacological properties such as antioxidants, anti-bacterial, and anti-fungi [8] - [12]. Thus, the use of material in natural textile coloring is expected to provide 2 (two) benefits at once, namely coloring and providing protection from attacks by free radicals and microorganisms.

Other than mangiferin, curcuminoids are one of the producers of natural textile dyes, yellow, resulting from the extraction of turmeric root (Curcuma longa $L$ ), with the main constituent known as curcumin, along with small amounts of demethoxycurcumin and bisdemethoxycurcumin [13]. As well mangiferin, a large number of previous studies have also been successful in proving the functionality of curcumin, which is not only able to color silk fibers in brilliant yellow but is also capable of providing other 
functional properties, such as antibacterial activity [14] and antioxidants [15]. Thus, the coloring of textiles using turmeric material will not only produce the appearance of brilliant yellow shades on the fiber, but also be able to make the related textile material odorless due to the minimal interaction between sweat users of textile products with some types of microorganisms that cause body odor.

\section{MATERIAL AND METHOD}

\section{A. Material}

The raw material used as a color producer in this study is mango and turmeric leaves, does not have special specifications. Turkish Red Oil (TRO) material used in this research was obtained from UD. Main Chemical SurabayaIndonesia. Alum (A12 (SO4) 3) which in this study played a dual role, as a mordanting agent and fixer and ash soda (Na2CO3) purchased from PT. Brataco Surabaya-Indonesia. Tunjung (FeSO4.7H2O) and lime (CaCO3), both of which were used as fixers in this study were purchased from UD. Jaya Murni Surabaya-Indonesia.

\section{B. Mordanting}

Mordanting is generally carried out to increase the interaction of coloring compounds with textile materials. This stage can produce more even and sharp coloring results. Mordanting is carried out in the following stages. Three pieces of $25 \times 25 \mathrm{~cm}$ textile material that will be colored, soaked in TRO $2 \mathrm{~g} / \mathrm{L}$ for 6 hours. The textile material is then rinsed by soaking it in 2 liters of water while still stirring using a magnetic stirrer and then aerated. The textile material is further processed with mordanting using alum and soda ash.

The mordant solution was prepared by dissolving 16.7 grams of alum and 4.2 grams of soda ash in 2 liters of water. The solution is stirred with the magnetic stirrer until it dissolves completely ( \pm 5 minutes). The solution is heated to $100{ }^{\circ} \mathrm{C}$, then a fabric is inserted into it while continuing to heat for up to 1 hour. The fabric is left in a submerged condition for 12 hours. Flushing the fabric is done by soaking in 2 liters of water which is stirred continuously using a magnetic stirrer for 10 minutes. The cloth is then dried and ironed. After that, the fabric is ready to be colored.

\section{Fixer Preparation}

To find high fastness in natural coloring, the natural coloring of textiles usually ends with fixation or color locking. In general, the preparation of the fixer solution is carried out by dissolving 50 grams of tunjung in 1 liter of air. The solution is formed and then left to settle, the clear side of the solution is used for the fixation process.

\section{Natural Dyeing}

Extraction of natural coloring compounds from mango and turmeric leaf material was carried out by the following procedure. Five hundred grams of raw material is cut into small pieces and mashed to form a puree. The puree is put into a beaker and is added with water in a ratio of $1: 10$. The raw material is then heated until the volume of the solution becomes half of the first. To get a more concentrated dye solution, heating can continue until the volume of the solution becomes one-third of the original. At the final stage of the preparation of natural dyes, filtering of the dye solution is used using filter gauze in order to separate the dye solution with residue. The filtered dye extract is then cooled and ready for use.

\section{E. Dyeing Procedure}

Fabric dyeing using natural dyes from the material of mango and turmeric leaves follows the procedure as follows. A total of $210 \mathrm{~mL}$ extracts of natural coloring were put into the dying place and then inserted into a $25 \times 25 \mathrm{~cm} \mathrm{(7}$ gram) cloth that had passed the mordanting stage. Coloring is done for 50 minutes (10x immersion x @ 5 minutes). At the next stage, the fabric sample is ready to be fixed.

\section{F. Fixation Procedure}

In the fixation process, the fabric goes down to $210 \mathrm{~mL}$ of fixer solution: (a) Iron (II) sulfate $\left(\mathrm{FeSO}_{4} \cdot 7 \mathrm{H}_{2} \mathrm{O}\right)$ (tunjung), (b) aluminum sulfate (alum) and (c) and calcium oxide $(\mathrm{CaO})$. Fabric samples are soaked in a fixer solution for 10 minutes. Fabric samples are then rinsed, washed and dried.

\section{G. Analysis}

To find out the color quality resulting from the natural dyeing procedure using mango and turmeric leaf material, a number of analyzes were carried out which included: (a) Shimadzu Diffuse Reflection Ultra Violet (DRUV) UV2401-PC Spectrophotometer using color intensity instrument to determine the strength the color of the hybrid produced; and (b) staining scale analysis carried out to determine hybrid color fastness resulting from natural coloring using mango and turmeric leaf material.

\section{RESULT AND DISCUSSION}

\section{A. Natural Hybrid Dyeing with mango and tumeric leaf material}

Hybrid dyeing is a coloring method by utilizing a combination of dyes or pigments to obtain a variety of color shades and high strength and colorfastness. Hybrid dyeing can also be one solution to the lack of abundance of one of the natural coloring material sources, given the combination of dyes that can produce the same type of chromophore and auxochrome will produce the same color. Textile dyeing results using more than one coloring material are expected to be able to be an alternative natural dyeing source material that is able to replace the role of seasonal material sources, through the appearance of the same color with strength and colorfastness that is not less strong. Thus, one of the weaknesses that have been triggering the assumption that the use of natural dyes in textile production is less practical can be overcome.

Before staining using natural dyes, fabric fibers will be prepared in advance through a number of stages, such as washing using TRO and mordanting using alum and soda ash. Fabric fiber preparation using TRO compounds aims to remove most or all of the contaminants found in the fabric fibers that will be colored. This treatment has an important 
role in removing various compounds, both compounds with the same type of charge as fiber and contaminant compounds that have different charges with fiber. Considering that fabric fibers are dominated by negatively charged hydroxide functional compounds, the presence of contaminant compounds with a positive charge will trigger interactions between the two, thus potentially blocking interactions that may occur between coloring compounds, especially those with a positively charged functional group. In line with this, although in the compound structure is dominated by the same functional group (negative) with fabric fibers, the deposition of a large number of these compounds also has the potential to prevent possible interactions between negative functional groups of fabric fibers with positive groups of natural coloring compounds. In Fig. 1 there is an illustration of interactions that can occur between functional groups of fabric fibers with specific contaminants and natural dyes.

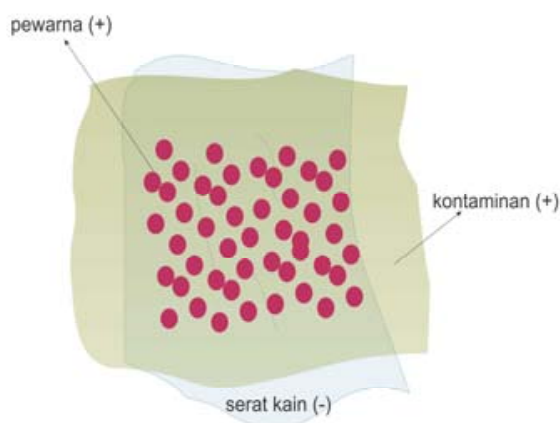

Fig. 1. Illustration of interactions that can occur between fabric fibers, contaminants and specific dyes

After ensuring the minimum contaminants contained in the fabric fibers, to optimize the interactions that occur between the functional groups of fabric fibers and coloring compounds, especially those that are negatively charged, the preparation of fabric fibers is followed by mordanting, which is the procedure of preparing fabric fibers through soaking fabric fibers in solution specific mordant. Not all chemical compounds can act as mordant compounds. Most of the mordanting functions are presented by complex metal compounds with more than one valence, such as A12 (SO4) 3 or better known as alum. The mordant compound acts as an intermediate compound that allows interaction between negatively charged fabric fibers and natural coloring compounds which are also dominated by the same charge. One of the positive charges of the mordant compound will interact with the negative charge of the fabric fiber and the remaining positive charge will interact with the negative group of the coloring compound. The greater the positive valence possessed by the mordant compound, the higher the quantity of dye bound, resulting in higher strength and color fastness. In Figure 2 there is an illustration of the interaction that occurs between the fabric fibers and the mordanting agent.

In figure 3, it appears the dye molecular structure of mangiferin is a green colorant contained in mango leaf extract. As seen in the molecular structure, mangiferin compounds are dominated by negatively charged hydroxide functional groups. Coloring compounds with negative charges such as mangiferin will not produce color when directly interacted with fabric fibers which are not through the previous mordanting process. However, in some cases, staining has been reported on the appearance of colors on fabric fibers that do not go through the mordanting stage. In such cases, it is predicted that a large number of coloring compounds have interacted with contaminants that are positively charged. This kind of contaminant compound is capable of carrying out the role as is the mordanting agent. However, it should be noted that in this case staining generally has a lower color strength with low fastness. This condition is triggered by the minimum interaction that occurs between fabric fibers and dyes due to the absence of high valence in the positive charge of the contaminant compound compared to most mordant compounds.

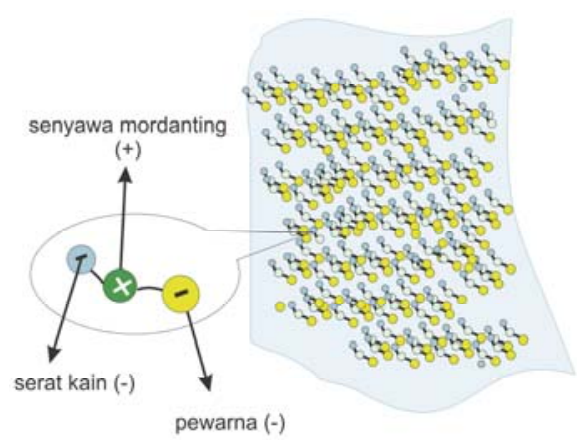

Fig.2. Illustration of interactions that can occur between fabric fibers with mordant compounds<smiles>O=c1c2cc(O)c(O)cc2oc2cc(O)c(C3O[C@H](CO)[C@@H](O)[C@H](O)[C@H]3O)c(O)c12</smiles>

Fig.3. The molecular structure of magiferin

In line with the molecular structure of mangiferin in mango leaf extract, turmeric extract also contains a natural coloring compound, namely curcumin, a bright yellow dye producer dominated by negatively charged functional groups, one of which is a hydroxide group. However, slightly different from mangiferin, in the turmeric extract there is also a complementary compound which also strengthens the appearance of typical yellow shades of turmeric, namely demethoxycurcumin (Fig. 5) and bisdemethoxycurcumin (Fig. 6).<smiles>COc1cc(/C=C/C(=O)CC(=O)/C=C/c2ccc(O)c(OC)c2)ccc1O</smiles>

Fig. 4. The molecular structure of curcumin 
<smiles>COc1cc(/C=C/C(=O)CC(=O)/C=C/c2ccc(O)cc2)ccc1O</smiles>

Fig. 5 .The molecular structure of demethoxycurcumin<smiles>O=C(/C=C/c1ccc(O)cc1)CC(=O)/C=C/c1ccc(O)cc1</smiles>

Fig. 6. The molecular structure of bisdemethoxycurcumin

In addition to the washing stages using TRO and mordanting using alum, the fixation stage uses three types of fixer compounds, is tunjung, alum and lime which are an integral part of the natural dyeing process. The fixation stage is done as a final stage, where the fixer compound will act as a color lock. The color locking mechanism that is carried out at the fixation stage is activated by minimizing the reactivity of active functional groups in coloring compounds through interactions that occur with various types of fixer compounds. However, in its development, almost most textile businesses do not understand the procedure for selecting fixer compounds, especially if they do not want the changes in color shades that appear. Tunjung, tawas and limestone are three types of fixer compounds that are widely used by textile businesses with natural dyes throughout Indonesia. To get color shades that are similar to the original extract, the fixer compound used must be ensured that it does not contain different chromophore and auxochrome groups with coloring extracts. In the coloring of fabric fibers using mangiferin dye which ends with a fixation process using tunjung, alum and lime each have resulted in the emergence of different shades of color with the dye extract, is blackish green, greenish yellow and yellow. While coloring with curcumin, each has produced the appearance of yellowish brown, yellow and cream shades from fixation using tunjung, tawas and lime. In table 1, there are a number of color shades resulting from staining using mangiferin, curcumin, and a hybrid of both.

TABLE 1. THE COLORATION OF THE DYEING RESULTS USING MANGIFERIN AND CURCUMIN

\begin{tabular}{|l|c|c|c|}
\hline \multirow{2}{*}{$\begin{array}{c}\text { Color } \\
\text { Composition }\end{array}$} & \multicolumn{3}{|c|}{ Fixer type } \\
\cline { 2 - 4 } & Tunjung & Alum & Lime \\
\hline $100 \%$ DM & & & \\
& & & \\
& & & \\
& & & \\
\hline
\end{tabular}

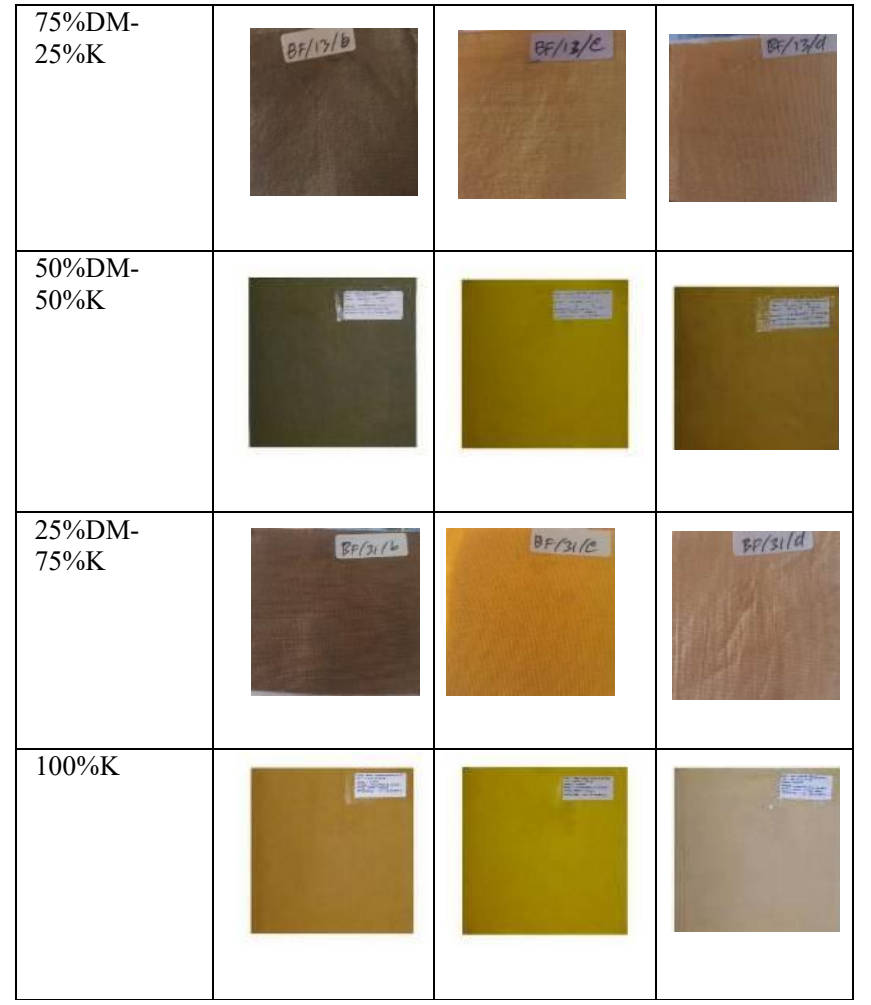

\section{B. Analysis}

In table 2, the color intensity produced by staining using mangiferin, curcumin, and hybrids of the two coloring compounds appear. The results of the color intensity analysis of each color composition showed that the coloring using mangiferin produced the best color intensity, amounting to $97.06 \%$, which resulted from fixation using a lime fixer, while in staining using curcumin, the highest intensity resulted from fixation using tunjung fixer (89, $73 \%$ ). Meanwhile, overall, hybrid coloring results 75\% DM / 25\% K; 50\% DM / 50\% K; and 25\% DM / 75\% K which ends with fixation using alum fixer produces the highest color intensity, each of which is $97.88 \% ; 76.53 \%$; and $87.63 \%$. These results indicate that hybrid staining with a comparable composition of mangiferin and curcumin is unable to produce color strength comparable to other compositions. This condition is predicted to be influenced by the high level of competition among mangiferin and curcumin compounds which actually reduce the strength of the color produced.

TABLE 2. COLOR INTENSITY RESULTING FROM STAINING USING MANGIFERIN AND CURCUMIN

\begin{tabular}{|c|c|c|c|}
\hline No. & Material & $\begin{array}{c}\text { Composition } \\
(\mathbf{\%} / \mathbf{v})\end{array}$ & $\begin{array}{c}\text { Color } \\
\text { Intensity }\end{array}$ \\
\hline 1 & DM1 & 100 & 88,96 \\
\hline 2 & DM2 & 100 & 79,89 \\
\hline 3 & DM3 & 100 & 97,06 \\
\hline 4 & K/DM1 & $25 / 75$ & 74,56 \\
\hline 5 & K/DM2 & $25 / 75$ & 97,88 \\
\hline 6 & K/DM3 & $25 / 75$ & 87,79 \\
\hline 7 & K/DM1 & $50 / 50$ & 57,36 \\
\hline 8 & K/DM2 & $50 / 50$ & 76,53 \\
\hline
\end{tabular}




\begin{tabular}{|c|c|c|c|}
\hline 9 & K/DM3 & $50 / 50$ & 72,38 \\
\hline 10 & K/DM1 & $75 / 25$ & 35,60 \\
\hline 11 & K/DM2 & $75 / 25$ & 87,63 \\
\hline 12 & K/DM3 & $75 / 25$ & 37,89 \\
\hline 13 & K1 & 100 & 89,73 \\
\hline 14 & K2 & 100 & 77,61 \\
\hline 15 & K3 & 100 & 81,55 \\
\hline $\begin{array}{r}\text { Note : } \\
1 .\end{array}$ & Tunjung, 2. Alum, 3. Lime \\
\end{tabular}

TABLE 3. COLORFASTNESS RESULTING FROM STAINING USING MANGIFERIN AND CURCUMIN AGAINST WET WASHING

\begin{tabular}{|c|c|c|c|}
\hline No. & Material & $\begin{array}{l}\text { Komposisi } \\
(\% \mathrm{v} / \mathrm{v})\end{array}$ & $\begin{array}{l}\text { Staining } \\
\text { Scale }\end{array}$ \\
\hline 1 & DM1 & 100 & 3 (enough) \\
\hline 2 & DM2 & 100 & 4 (good) \\
\hline 3 & DM3 & 100 & 3-4 (worth) \\
\hline 4 & K/DM1 & $25 / 75$ & 3-4 (worth) \\
\hline 5 & K/DM2 & $25 / 75$ & 2 (less) \\
\hline 6 & K/DM3 & $25 / 75$ & 2-3 (less) \\
\hline 7 & K/DM1 & $50 / 50$ & 4 (good) \\
\hline 8 & K/DM2 & $50 / 50$ & 3 (less) \\
\hline 9 & K/DM3 & $50 / 50$ & 2 (less) \\
\hline 10 & K/DM1 & $75 / 25$ & 3-4 (worth) \\
\hline 11 & K/DM2 & $75 / 25$ & 2-3 (less) \\
\hline 12 & K/DM3 & $75 / 25$ & 2-3 (less) \\
\hline 13 & $\mathrm{~K} 1$ & 100 & 3-4 (worth) \\
\hline 14 & $\mathrm{~K} 2$ & 100 & 3-4 (worth) \\
\hline 15 & K3 & 100 & 2-3 (less) \\
\hline \multicolumn{4}{|c|}{ Note : } \\
\hline \multicolumn{4}{|c|}{ 1. Tunjung } \\
\hline \multicolumn{4}{|c|}{ 2. Alum } \\
\hline \multicolumn{4}{|c|}{ 3. Lime } \\
\hline
\end{tabular}

Table 3 shows the color fastness scale of each dye composition and fixer type. The results of staining scale analysis showed the effectiveness and efficiency of tunjung as a fixer compound for staining using mangiferin and curcumin. This condition is evident from the higher staining scale resulting from fixation using tunjung compared to the other two types of fixers, namely alum and lime. However, it is important to note that the high complexity and quantity of chromophore and auxochrome groups found in fixer tunjung compounds have caused significant color changes produced compared to the original extract dyes. Therefore, to get a color feel that more closely resembles the original extract color, alum fixer is the best alternative that can be used.

\section{CONCLUSION}

In this study natural dyeing procedures have been developed using hybrid dyes that combine mangiferin and curcumin which ends with fixation using tunjung fixers, alum and lime. In general, the results of the analysis showed the appearance of color shades which were yellow, brown and green gradations with color intensity of $35.60 \%$ $97.88 \%$ and colorfastness of wet washing in the range of staining scale 2 (less) - 4 (good). In addition, the results of the analysis show the tendency for the darkest (blackish) color to emerge from the use of a raised fixer, and the color shades closest to the color of the extract from the use of alum fixers.

\section{ACKNOWLEDGMENT}

Thank you to the Ministry of Research and Technology of the Republic of Indonesia Higher Education for providing financial support through the National Strategic Research Program - Institution of Budget Year 2018

\section{REFERENCES}

[1] N, Kusumawati, A. Kistyanto, and S. Muslim, "The effect of blending composition against latched power and the resistance of batik wax against cracking and clkaline chemicals," International Journal on Advanced Scince Engineering Information Technology, May 2012, vol. 7, pp.1141-1147.

[2] Suhartini, N. Aini, A. Muid, U. Ciptomulyono, and M. Singgih, Prosiding seminar nasional manajemen technologi xii, Program studi MMT:ITS.

[3] N. Kusumawati, A. Wijiastuti, E. Rahmadyanti,"Operating condition optimization on indonesia batik dyes wastewater treatment by fenton oxidation and separation using ultrafiltration membrane," Journal of Environmental Science and Engineering, May 2012, vol. 1, pp. 672682.

[4] K. Hunger and U. Sewekow, Health and Safety Aspects, Hunger K ed, Weinhem: Wiley-VCH

[5] N. Kusumawati, S. Muslim, and A. Kistyanto, "Operational condition optimization on blacu fabric dyeing technology (case study: mordanting influence on naphtol color quality and mechanical strength of blacu," Research Journal Pharmaceutical, Biological \& Chemical Sciences, September 2016, vol. 7, pp. 672.682.

[6] G. Crini, "Non-conventional low-cost adsorbents for dye removal: a review,'Bioresource technology, 2016, vol. 97, pp. 1061-1085.

[7] S. Kasmudjo, Prossiding seminar nasional masyarakat peneliti kayu Indonesia (MAPEKI) XIV. Masyarakat peneliti kayu Indonesia.

[8] H. Masibo and Q. He, "Major mango polyphenols and their potential significance to human health," Compr. Rev. Foof Sci. Food Saf, September 2008, vol. 7, pp. 309-319.

[9] S.M.R. Ribeiro and A. Schieber, Bioactive compound in mango(Mangivera indica L.), R.R Waston, V.R. Preedy ed, London:Academic Press.

[10] G.D. Noratto, M.C. Krenek, S.T. Talcott, P.C. Stringheta, and S.U.M. Talcott, "Anticarsinogenic effect of polyphenolics from mango (mangivera indica) varieties," J. Agric. Food Chem, March 2010, vol. 58, pp. 4104-4112.

[11] N. Wauthoz, A. Blade, E.S. Balde, M.V. Damme, and P. Duez, "Ethnopharmacology of mangifera indica 1. Bark and pharmachological syudiesof its main c-glucosylxanthone, mangiferin," Int J. Biomed Pharm. Sci, September 2017, vol. 1, pp.112-119.

[12] A.J. Nuñez-Selléz, H.T. Vélez Castro, J. Agüero-Agüero, J. González, F. Naddeo, F. De Simone, and L. Rastrelli, "Isolation and quantitative analysis of phenolic antioxidants, free sugars, and polyols from mango (Mangifera indica L.) stem bark aqueous decoction used in Cuba as a nutritional supplement," J. Agric. Food Chem, 2002, vol. 50, pp. $762-766$.

[13] M. Mirjalili and L. Karimi, "Antibacterial dyeing of polyamide using turmeric as a natural dye," Autex Res J, 2013, vol. 13, pp. 51-56.

[14] S.M. Ghoreishian, L. Maleknia, H. Mirzapour , and M. Norouzi, "Antibacterial properties and color fastness of silk fabric dyed with turmeric extract," Fiber Polym, 2013, vol. 14, pp. 201-207. 
[15] Y. Zhou, J. Zhang, R. Tang, and J. Zhang, "Simultaneous dyeing and functionalization of silk with three natural yellow dyes" Ind Corp
Prod, 2015, vol. 64, pp. 224-232. 